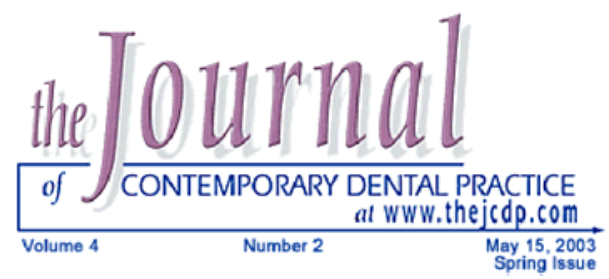

\title{
Ailing and Failing Endosseous Dental Implants: A Literature Review
}

\author{
Eric T. Ashley, DDS; Lemuel L. Covington, DMD \\ Barry G. Bishop, DDS; Lawrence G. Breault, DMD, MS
}

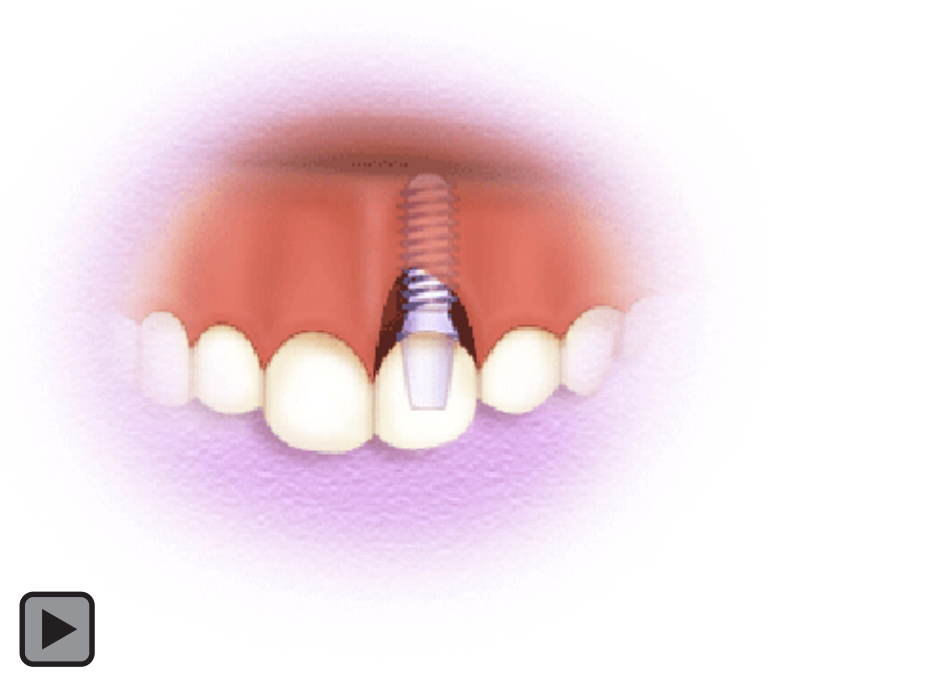

Abstract

Although the overall success rate of implant dentistry is very high, dental implants occasionally fail. It is essential for the clinician to recognize unhealthy implants and to determine whether they are ailing, failing, or failed prior to beginning any salvage efforts. Ailing and failing implants are amenable to therapy. Implants diagnosed as failed should be removed. This review provides the reader with information on non-surgical and surgical therapies available for managing ailing and failing implants. Undoubtedly, the best steps to avoid encountering ailing or failing implants involve proper case selection, excellent surgical technique, placing an adequate restoration on the implant, educating the implant patient to maintain meticulous oral hygiene, and evaluating the implant both clinically and radiographically at frequent recall visits.

Keywords: Ailing implant, failing implant, failed implant, implantoplasty

Citation: Ashley ET, Covington LL, Bishop BG, Breault LG. Ailing and \& Failing Endosseous Dental Implants: A Literature Review. J Contemp Dent Pract 2003 May;(4)2:035-050.

(C) Seer Publishing 


\section{Introduction}

Throughout the history of dentistry, clinicians and patients have struggled with options for replacing missing teeth. Treatment options have evolved from acrylic dentures to metal framework removable partial dentures to fixed partial dentures. Recently, titanium implants have joined the armamentarium of the restorative dentist. Implants are now becoming mainstream treatment in dentistry. The benefits of endosseous dental implants are many.

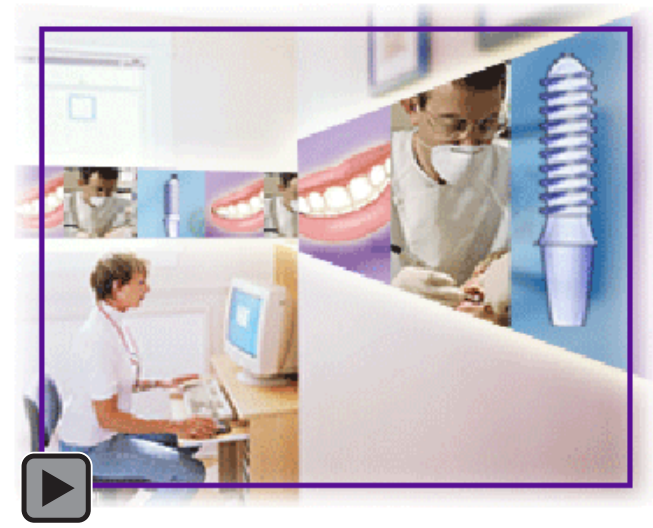

Dental implants provide the patient with a fixed anchor for a tooth or teeth that need not be removed at night or for cleaning. Implants also do not require preparation of healthy, asymptomatic teeth. In addition, the edentulous patient is afforded a prosthesis that is both stable and, in most cases, highly esthetic.

Implants are being placed in greater numbers each year as patients become more familiar with their advantages. Once the dentist introduces implants as a treatment option, the patient may access information using resources such as the Internet to learn more about this treatment modality. As a result, today's dental consumer is better informed and more often requests dental implants as their treatment of choice.

Dental implants are becoming more predictable. Studies have demonstrated success rates ranging from $80-92 \%$ success for the maxilla over 5 to 10 years. ${ }^{1,2}$ Other studies have reported long-term success rates for the maxilla at $92 \%$ and the mandible at $94 \%$ at 5 years ${ }^{3}$ with up to $78 \%$ success in the maxilla and $86 \%$ success in the mandible at the 15-year time period. ${ }^{4}$ Advances in surgical procedures, such as maxillary sinus lifts, lateral inferior alveolar nerve placement, and guided bong regeneration (GBR) allow the practitioner to place implants in patients that would not have received this treatment option 10 years ago. ${ }^{5-9}$

Although the success rate of implants is very high, implants occasionally fail. This review provides the reader with information on therapies available for treating ailing and failing implants. In many cases, with proper diagnosis and treatment, ailing and failing implants may be indefinitely retained.

\section{Success}

Osseointegration was the hallmark of success in implant dentistry in the 1980s. It was believed an implant was successfully integrated when there was direct contact between bone and the titanium implant (at the light microscopic level) with no fibrous connective tissue interface. ${ }^{10}$ However, the criteria for success have evolved beyond the initial goal of osseointegration. Implant success in the $21^{\text {st }}$ century involves other factors including: stability of the implant; adequate radiographic bone levels; lack of symptoms or evidence of infection; minimal probing depths around the implant, and the ability of the patient to keep the area clean. ${ }^{11}$

\section{Failure}

Clinically, lack of osseointegration leads to implant mobility and subsequent failure. Therefore, a mobile implant is a failed implant. A failed implant also may exhibit a dull sound upon percussion and/or demonstrate a peri-implant radiolucency (Figure 1).

Non-functional, failed implants must be removed (Figure 2) to prevent the associated bone loss from continuing. ${ }^{12}$ The option of removing the

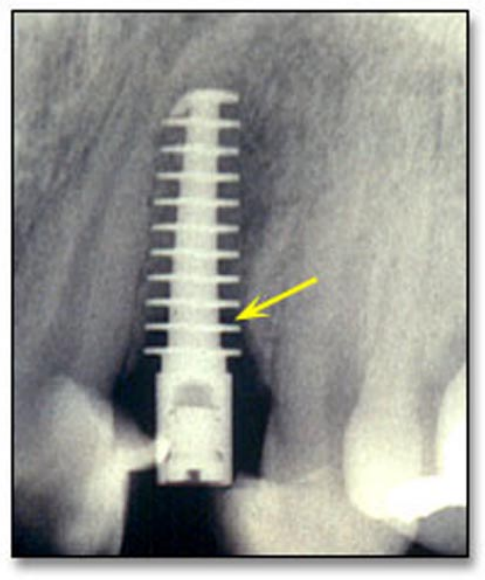

Figure 1. Failed implant with complete radiographic bone loss.

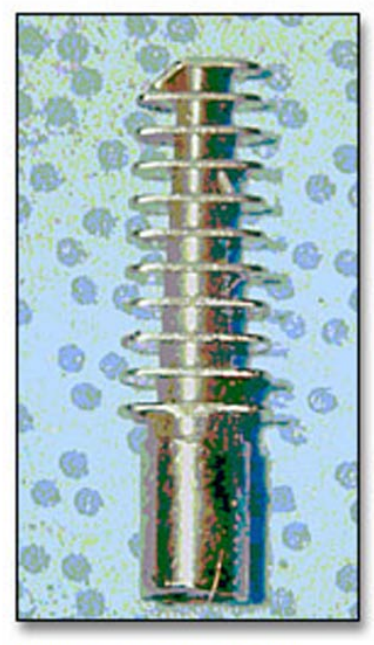

Figure 2. Removed failed implant. 
implant and allowing for healing and then replacement of another implant should not be ruled out.

Implants fail for a variety of reasons. Some studies have related failures to biological or microbiological factors ${ }^{13-17}$, while others attribute dental implant failure to biomechanical factors, biomaterial factors, or implant surface treatments and characteristics. $^{18,19}$

Improper patient selection is a significant reason for failure. Obviously, a patient unmotivated to control plaque around natural teeth would not be a good candidate for dental implants. Implants are doomed to fail when placed in patients having insufficient quality and/or quantity of bone to support the implant fixture. $^{20}$

Jaffin and Berman ${ }^{21}$ report a 5 year success rate of 1,054 Branemark (screw type) implants placed in private practice with regards to bone quality. Type I, II, and III bone offer good strength, in contrast to Type IV bone which has a thin cortex, low trabecular density, and poor medullary strength. Only $3 \%$ of fixtures placed in Types I, II, and III bone were lost compared to a $35 \%$ failure rate of implants placed in Type IV bone. However, bone quality may be less of a concern when cylinder type implant fixtures are utilized. Fugazzotto et al. $^{22}$ demonstrated an absolute success rate of $97.5 \%$ over 5 years with this type of implant.

Patients that smoke cigarettes have demonstrated an increase in implant failures. Overall failure rates have been reported as $11.28 \%$ for smokers compared to $4.76 \%$ for non-smokers. ${ }^{23}$ Additionally, failure rates were higher in the posterior maxilla (19.1\%) and the anterior maxilla (16.82\%), while mandibular failure rates were between $4 \%$ and $5 \%{ }^{23}$

Finally, systemic health of the patient is important when considering implants. Recent studies have demonstrated similar failure rates between wellcontrolled diabetics and non-diabetic controls ${ }^{24}$ or only slightly higher failure rates with Type 2 (non-insulin dependent) diabetics. ${ }^{25}$ Of course, uncontrolled diabetic patients are poor candidates for any surgical procedure.

Inferior surgical technique is another possible cause of implant failure. During surgical placement, implant failure may result from inadequate irrigation of the surgical site or from using low torque and excessive drill speed during placement. Failure results from excessive temperature elevation in bone during placement, leading to necrosis of the supporting bone around the implant. ${ }^{26}$

Inadequate implant restorations also may contribute to implant failure. Restorations placed on endosseous implants may cause traumatic occlusion, leading to failure. ${ }^{27,28}$ Additionally, poorly restored implants may have overhangs or be overcontoured, which may lead to plaque accumulation and eventual failure.

\section{Ailing vs. Failing Implants}

Clinically unhealthy implants are classified as "ailing" or "failing."29,30 It is necessary to distinguish between an ailing versus a failing implant to determine the treatment steps necessary to salvage the unhealthy implant. Implants exhibiting soft tissue problems exclusively are classified as ailing and have a more favorable prognosis. ${ }^{30,31}$ (Figures 3 \& 4)

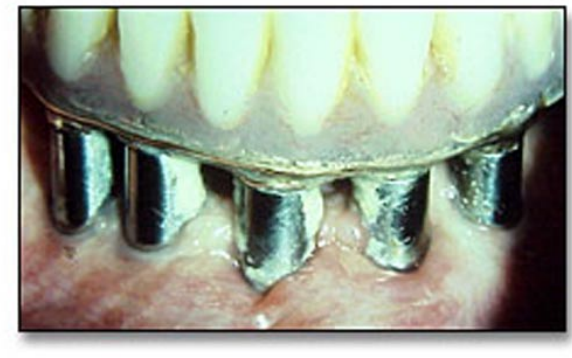

Figure 3 . Ailing implants secondany to calculus.

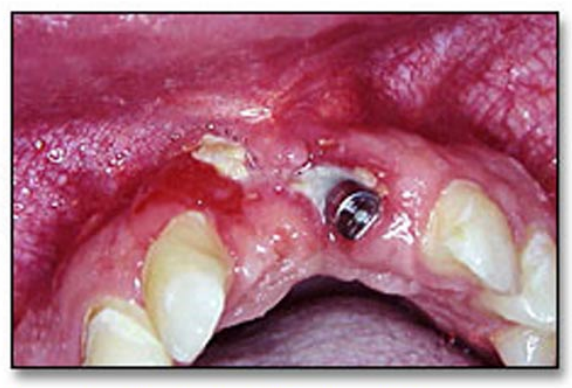

Figure 4. Ailing implant \#g with soft tissue involvement only.

Peri-implant mucositis involves inflammatory changes confined to the soft tissue surrounding an implant. ${ }^{32}$ Therefore, an implant exhibiting peri-implant mucositis is an ailing implant. In some instances, the ailing implant may have exhibited early bone loss along with soft tissue pocketing. However, this bone loss tends to become static at 
the 3- to 4- month maintenance checks. A lamina dura indicating a state of chronicity also may be present at the borders of the osseous defect. ${ }^{30,31}$

In contrast, the failing implant may show evidence of pocketing, bleeding upon probing, purulence, and indications the bone loss patterns are progressing despite previous therapy. ${ }^{30-33}$ Therefore, an implant that is progressively losing its bone anchorage, but is still clinically stable, can be defined as failing (Figure 5).

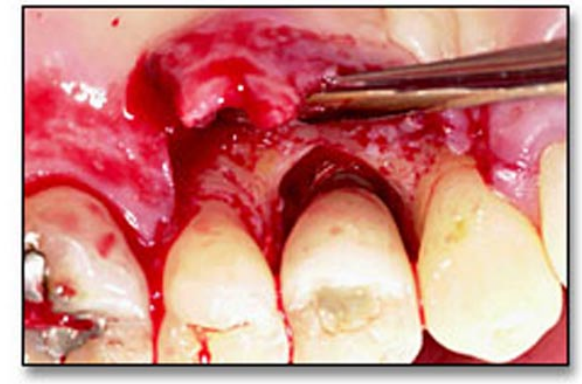

Figure 5 . Failing implant demonstrating vertical bone loss.

Failing implants have a poorer prognosis. However, if properly recognized and treated, a failing implant may be saved. ${ }^{29-32}$ Microflora associated with failing dental implants are identical to those found in chronic adult periodontitis. ${ }^{15-17,34}$ This microflora triggers inflammation and bone loss and is termed peri-implantitis. ${ }^{32}$ Peri-implantitis occurs when there is progressive peri-implant bone loss in conjunction with a soft tissue inflammatory lesion. ${ }^{32}$

Historically, other signs and symptom markers have been used to classify the ailing and failing implant. Tissue tone, pocket depth, attachment levels, bleeding on probing, suppuration, cervical fluid flow, plaque index, gingival index, mobility, oxygen tension levels, tissue collagenase activity, radiographic evaluation, and microbiological characterization of subgingival flora have all been utilized in implant classification. ${ }^{16,17,34-36}$

\section{Treatment Options}

Treatment options for ailing and failing implants are varied. The clinician should start conservatively and progress to more aggressive therapy. The overall goal of therapy is to establish a functional restoration and acceptable esthetics. ${ }^{29-31}$ Therefore, any therapy provided should arrest further loss of bone support and re-establish a healthy peri-implant mucosal seal. ${ }^{29-31}$

\section{Non-Surgical Therapy}

The most conservative approach to treatment involves non-surgical therapy. ${ }^{29,32}$ This treatment modality includes three subcategories: pharmacological therapy, occlusal therapy, and mechanical debridement. Pharmacological therapy for patients presenting with an ailing implant involves subgingival irrigation for 10 days to 3 weeks ( 2 to 3 times per 24 hour time period). This may be completed at home following careful instructions from the clinician or dental hygienist. Chlorhexidine is most often prescribed because of its antimicrobial effect and substantivity at the affected site. However, no scientific data has validated the effectiveness of chlorhexidine when used in this manner. In fact, some clinicians have found this therapy to be ineffective. Their belief is low concentrations of chlorhexidine $(0.12 \%$ to $0.2 \%)$, combined with cervical fluid dilution and the apparent protective function of blood serum, may result in the ineffectiveness of chlorhexidine. ${ }^{11}$

Other pharmacological therapies include local application of tetracycline fibers and systemic antibiotics. ${ }^{31,32}$ Bacteria associated with failing implants have been found to be sensitive to the following antibiotics: penicillin $\mathrm{G}$, amoxicillin, combination of amoxicillin and metronidazole, and amoxicillinclavulanate. ${ }^{9,10}$

Mombelli and Lang ${ }^{37}$ treated nine peri-implantitis sites non-surgically through local removal of plaque deposits, polishing accessible surfaces with pumice, subgingival irrigation of peri-implant pockets with $0.5 \%$ chlorhexidine, and systemic antimicrobial therapy for 10 consecutive days. Treatment resulted in a mean reduction of probing pocket depth of $2.5 \mathrm{~mm}$ in conjunction with a gingival recession of $1 \mathrm{~mm}$ and some re-growth of bone seen radiographically.

Occlusal interferences may contribute to ailing and failing implants. ${ }^{38,39}$ Occlusal adjustment is necessary when premature contacts or interferences are present. The implant prosthesis also must be examined when grinding, bruxing, or other parafunctional habits are evident. The clinician must correct these occlusal errors to prevent overloading of the implant. Nightguard therapy may be indicated as well. Although occlusal therapy seems logical, there is currently no scientific evidence to support its use. 
A third non-surgical therapy recommended for treating the ailing or failing implant is mechanical debridement. ${ }^{32,33}$ Local debridement of tissues surrounding an implant using either plastic hand instruments or ultrasonic instruments with a plastic tip has been suggested. Plastic instruments are necessary to debride plaque from titanium dental implants without damaging the soft titanium surface. Although it is important to note that regular toothbrush bristles can roughen the dental implant, mechanical instrumentation to remove bacterial deposits also may damage the implant surface when performed with metal instruments harder than titanium..$^{33,40,41}$ In a comparative in vivo study, the surface texture of titanium implant abutments were evaluated after exposure to plastic scalers, an air-powdered abrasive system, and polishing with rubber cup and pumice. None of these methods appeared to roughen the surface. The rubber cup with pumice actually provided the smoothest polished abutment. ${ }^{41}$

\section{Surgical Therapy}

The clinician may use a surgical approach when non-surgical therapies are not indicated or are unsuccessful. In an implant subjected to "infectious failure," the assumption is implant surfaces exposed to periodontopathogens have become contaminated with endotoxins that may interfere with the repair process. ${ }^{34}$ An endotoxin is a heat stable, lipopolysaccharide complex found in the cell wall of many Gram-negative microorganisms. It is pro-inflammatory, cytotoxic, pyrogenic and has been implicated in the causation of periodontal disease. ${ }^{42}$ As long as endotoxins are present, there can be no biological repair.

The first step in surgical therapy is exposing and treating the bacterially contaminated implant surface (Figure 6). The clinician must remove

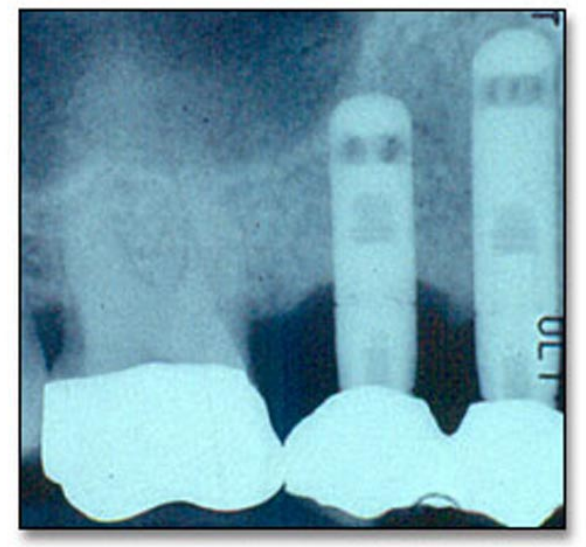

Figure 6. Radiograph of a failing HA coated implant. endotoxins from the surface of the failing implant. This is especially true of hydroxyapatite (HA) coated surfaces. ${ }^{11,30-32,36}$ The HA coating may be pitted, cracked, and brownish in color and may show areas of resorption down to the base metallic substrate (Figure 7). These surface changes result from the infectious aspects of disease and inflammation. As the $\mathrm{pH}$ in the area becomes lower during inflammation, the HA surface begins to decalcify and/or resorb. This resorption process is similar to the effects of periodontal disease, as the implant exhibits the subsequent loss of connective tissue attachment and establishes an osseous defect. ${ }^{32,43}$

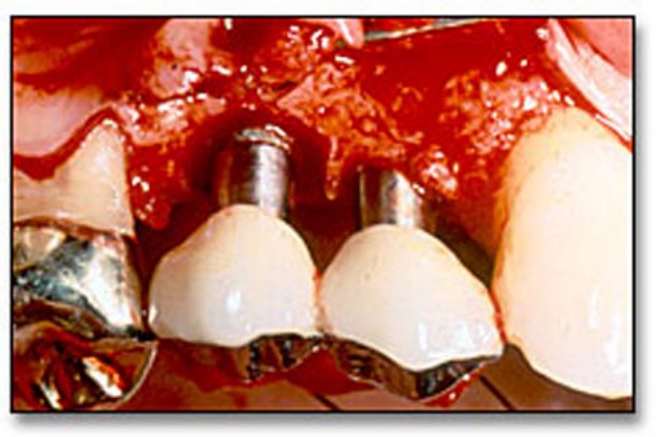

Figure 7. Failing implant exposing contaminated HA co ating of implant.

The literature suggests using chemical agents to detoxify the surface of the failing implant. The rationale for their use is the subgingival flora associated with dental implants have been shown to be very similar to those associated with natural teeth. Chemotherapeutic agents such as chlorhexidine gluconate, stannous fluoride, and tetracycline are antimicrobials and/or antibiotics, which theoretically would not only kill the periodontopathic bacteria but also would remove endotoxins from a root implant surface.

Some of these agents appear to be more effective than others. Zablotsky et al. ${ }^{11}$ studied the ability of various chemotherapeutics to detoxify infected HA-coated implant surfaces. He used strips infected with endotoxins isolated from purified outer membranes of $E$. coli labeled with radioactive C14. The strips were treated with citric acid, stannous fluoride, tetracycline, chlorhexidine, hydrogen peroxide, polymyxin B., or a modified plastic Cavitron $^{\circledR}$ (Dentsply York, PA 1-800-989-8826) tip or a control. The tetracycline, hydrogen peroxide, and polymyxin $B$ treated groups were not effective in removing endotoxins when compared to the distilled water burnished group (control). How- 
ever, the citric acid-tested group and the strips treated with the plastic Cavitron ${ }^{\circledast}$ tip were superior to the other treatment groups in endotoxin removal. These findings agree with other studies that concluded detoxification of the infected HAcoated implant surface using citric acid or scaling the surface with plastic-tipped instruments may be beneficial in the surgical repair of the ailing implant. ${ }^{44,45}$

Wittrig et al. ${ }^{44}$ also investigated cellular attachment and growth of fibroblasts on HA-coated treated strips. They reported implant surface treatment with tetracycline or citric acid resulted in greater cellular attachment and growth as compared with untreated groups, while Polymyxin $B$, hydrogen peroxide, stannous fluoride, and chlorhexidine treatment allowed for cell coverage and morphology similar to untreated controls, (i.e., neither stimulating, inhibiting, or affecting cell attachment and growth to any degree). Use of a plastic Cavitron $^{\circledR}$ tip also seemed to stimulate cell attachment. ${ }^{44,45}$

Following debridement of the surgical area and removal of the infected and contaminated hydroxyapatite, the implant surface should be detoxified with a substance such as tetracycline paste (TCN). Typically, $250 \mathrm{mg}$ of TCN is mixed with saline in a dappen dish and applied to the metallic implant surface using a cotton pledget or camel's hair brush. TCN is intentionally left on the implant surface and the defect is then grafted with regenerative materials. TCN should be left on the surface to provide additional antimicrobial benefits as well as to stimulate connective tissue healing as reported by Wittrig. ${ }^{44}$

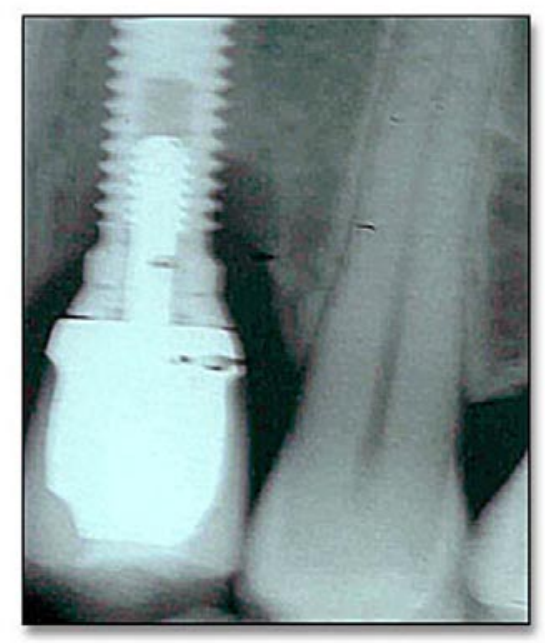

Figure 8. Radiograph of a failing implant.

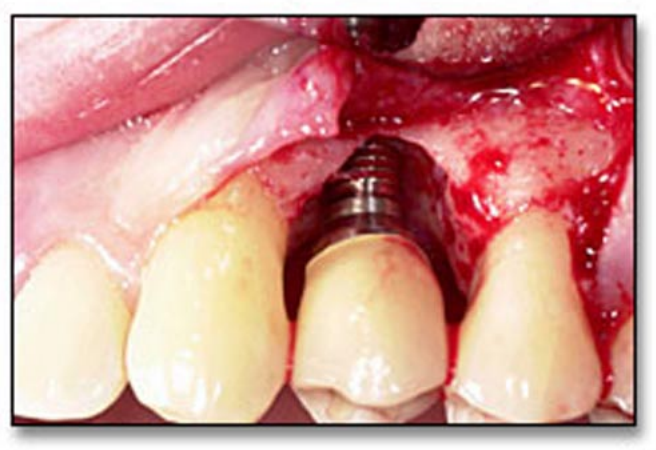

Figure 9 . Failing implant site prepared for bone graft.

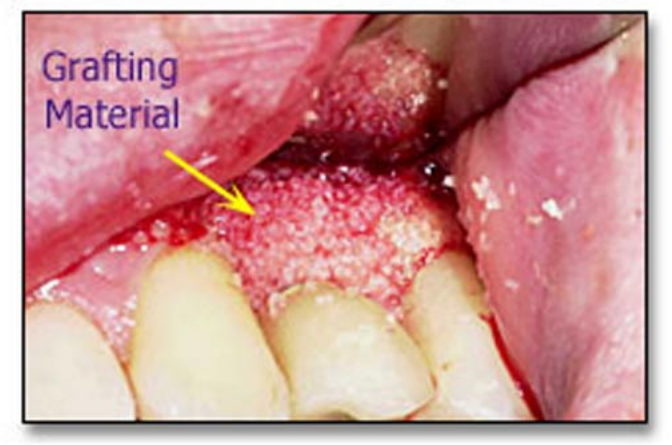

Figure 10. Failing implant grafted with demineralized freeze-dried bone allograft (DFDBA).

Once the implant is decontaminated, the next step is to regenerate or obliterate the osseous defect with a grafting material (Figure 8, 9, and 10). Bone-grafting materials fall into three main categories: autografts, allografts, and alloplastic grafts. Recently developed xenografts are also gaining increased attention. ${ }^{46}$ Xenografts are grafts from other species. One type of xenograft is bovine bone. ${ }^{46}$ It is believed bovine bone and especially biologic membranes made with bovine dura mater could possibly be contaminated with bovine spongiform encephalopathy ("mad cow disease"), although investigation of the production steps of bovine bone have determined this material does not present a risk to transmission. ${ }^{47}$

An autograft is tissue transferred from one position into a new position in the body of the same individual. It may be composed of cortical, cancellous, or combined cortical-cancellous bone containing within its matrix some post-osteogenic proteins capable of actual bone induction. ${ }^{48}$ Harvested bone from an edentulous area and placed around an implant site is one example of an autograft. 
Allografts, such as demineralized, freeze-dried bone (DFDBA), are tissue grafts from members of the same species, but of non-identical genetic composition. These may offer some bone-inductive capacity comparable to autografts. ${ }^{49}$ Lyophilized (freeze-dried), decalcified bone alone, or mixed with an antibiotic such as TCN may be used in therapeutic procedures. ${ }^{50}$ It is hypothesized this bone matrix contains a protein substrate that induces bone formation. Bone Morphogenic Protein (BMP) is believed to become available during decalcification of the lyophilized bone. ${ }^{51-53}$ Allograft material is used to treat most surgical periodontal defects and to repair failing implants after detoxification because of the relative limited availability of autograft material. ${ }^{12,54}$

Alloplastic grafts are synthetic graft materials that can be used as biocompatible "fillers" in helping to maintain bone and soft tissue height. They are classified as osteoconductive or osteophilic, which provides an environment for bone formation by means of a scaffolding or matrix configuration. ${ }^{55,56}$

One such alloplast is Bioplant $\mathrm{HTR}^{\circledR}$ (Bioplant, Inc. South Norwalk, CT 1-800-432-4487), a synthetically-derived material composed of microporous beads made up of polymethylmethacrylate (PMMA) and polyhydroxyl/ethylmethacrylate (PHEMA) coated with resorbable calcium hydroxide. $^{57}$ Examples of other alloplasts include: Biogran $^{\circledast}$ (3i, Inc. Palm Beach Gardens, FL 1-800342-5454), which is a granular material consisting of calcium, silicon, sodium, and potassium (Bioactive Glass) and Interpore $200^{\circledR}$ which is a a porous hydroxyapatite graft material (Interpore Cross, Irvine, CA, 1-949-453-3200).

The decision to utilize an alloplast or an allograft depends on the effectiveness of the detoxification of the implant surface. If the surface is clean and detoxified, with all exposed areas of the implant visualized and instrumented, it is possible to graft with an allograft material such as DFDBA to achieve biologic healing. ${ }^{32,43}$ However, if the implant surface cannot be cleaned and detoxified (due to vents, holes in the implant fixture, or tortuous osseous defects not accessible to instrumentation), it is advisable to graft with an alloplast material such as HA (particulate form), HTR, or Bioactive Glass. Alloplasts provide a physical, biocompatible "fill," minimize probing depth, support the mucoperiosteal flap, and help prevent further epithelial invagination. ${ }^{30}$

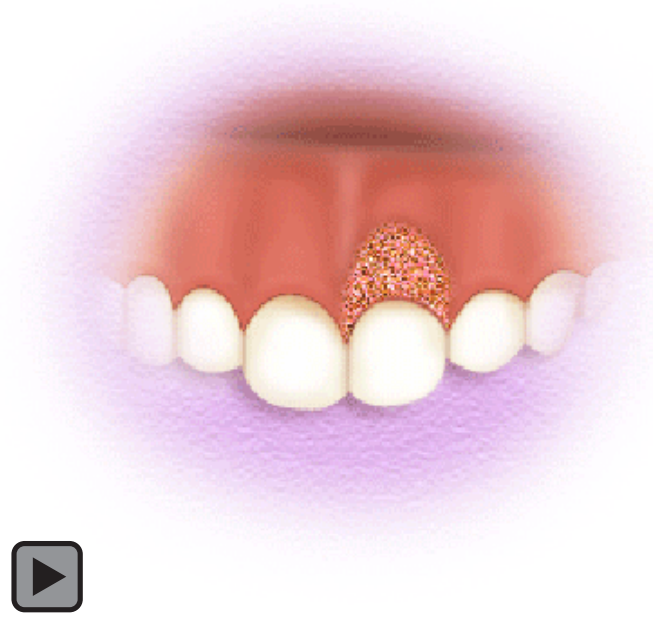

In conjunction with the various grafts discussed for bone regeneration around failing implants, clinicians also may use membranes to keep these grafts in the desired location. ${ }^{43}$ W.L. Gore \& Associates (Flagstaff, AZ 1-800-528-8763) pioneered both resorbable and non-resorbable membranes. Resorbable membranes are most commonly used today. Some examples include: Bio-Gide ${ }^{\circledR}$ (Osteohealth Co., Shirley, NY, 1-800-874-2334). Bio-Gide ${ }^{\circledR}$ is a type I and III porcine derived collagen. Other resorbable membranes include: vicryl mesh, demineralized freeze-dried lamellar cortical bone strips, freeze-dried dura mater, and crosslinked bovine collagen. ${ }^{43}$ Non-resorbable membranes are less commonly used because of the requirement for an additional surgery to recover the intact membrane.

Danesh-Meyer ${ }^{9}$ reported partial bone fill around failing implants using guided bone regeneration (GBR) alone or in combination with autogenous bone grafts or various types of allografts and alloplasts. He suggested microbial leakage at the abutment-implant junction might influence the outcome of GBR and, therefore, recommended the surgical area be isolated from the oral cavity with full-flap coverage of the membrane barrier.

Bone resection is an alternative implant surgical therapy. ${ }^{32}$ Full-thickness flap management is utilized to access the surgical area. Osseous resective therapy is used to correct horizontal bone loss, moderate $(<3 \mathrm{~mm})$ bone defects, one and two-wall defects with low regenerative potential, and to reduce overall probing depth. ${ }^{32}$ The clinician selects the appropriate surgical technique based on the type of osseous defect surrounding the failing implant. 


\section{Maintenance}

Regular professional maintenance is necessary to detect and manage implants that are ailing, failing, or have failed. Clinicians must keep in mind periodontal pathogens can cross-infect in the oral cavity. Gouvoussis et al. ${ }^{15}$ reported the transmission of periodontopathic organisms from active periodontal sites to implant sites in the same mouth is a likely event. The clinician should implement a clinical protocol that includes the elimination of periodontal disease in prospective implant patients.

Maintenance of an implant site is facilitated when implant surfaces coronal to the alveolar crest are smooth and clean. Implantoplasty involves using high-speed finishing and polishing burs to produce a smooth, continuous titanium surface on implants having exposed threads, roughened topography, or coated with HA (Figure 11). Implantoplasty is performed prior to beginning osseous resective therapy and must include copious irrigation to minimize excessive heat. ${ }^{32,58}$

The implant patient should return to the dental office every three months. During this recall appointment, probing around the implant is neces-

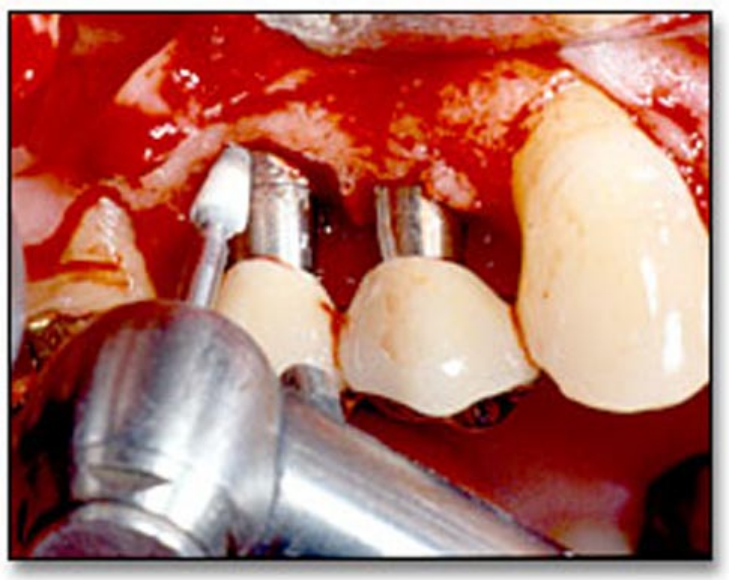

Figure 11. Implantoplasty removing contaminated HA coating of implant. sary only when pathology is suspected. Probing should be minimal and accomplished using a plastic-tip probe. It is advised to remove the implant superstructure (if retrievable) and abutment every 18-24 months for cleaning in an ultrasonic solution. ${ }^{58}$ Radiographs should be exposed every 12 months to detect any bone level changes. ${ }^{58}$

It is imperative the implant abutment surface be kept smooth to facilitate plaque control procedures by the patient. ${ }^{40,41}$ Dental hygienists should scale the area supragingivally and only very slightly subgingivally. Scalers must have plastic tips and be soft enough to avoid roughening or scratching the implant surface. In addition, scalers must be strong enough to engage calculus without bending or breaking the tip. The clinician and hygienist must reinforce plaque control with the implant patient.

\section{Summary}

Fortunately, unhealthy implants are uncommon because of the high success rate of implant therapy in the $21^{\text {st }}$ century. However, it is essential for the clinician to recognize unhealthy implants and to determine whether they are ailing, failing, or failed prior to beginning any salvage efforts. Ailing and failing implants are amenable to therapy. Implants diagnosed as failed should be removed.

Several techniques for identifying and managing ailing and failing implants have been presented in this review. Undoubtedly, the best steps to avoid encountering ailing or failing implants involve proper case selection, excellent surgical technique, placing an adequate restoration on the implant, educating the implant patient to maintain meticulous oral hygiene and evaluating the implant both clinically and radiographically at frequent recall visits. More research is necessary in this area to validate the current therapies used in managing ailing and failing implants. 


\section{References}

1. Branemark PI, Svensson B, van Steenberghe D. Ten-year survival rates of fixed prostheses on four or six implants ad modum Branemark in full edentulism. Clin Oral Implants Res. 1995 Dec;6(4): 227-31.

2. Jemt T, Lekholm U. Implant treatment in edentulous maxillae: a 5-year follow-up report on patients with different degrees of jaw resorption. Int J Oral Maxillofac Implants. 1995 May-Jun;10(3):303-11.

3. Adell R, Eriksson B, Lekholm U, et. al. Long-term follow-up study of osseointegrated implants in the treatment of totally edentulous jaws. Int J Oral Maxillofac Implants. 1990 Winter;5(4):347-59.

4. Lekholm U, van Steenberghie D, Herrimann I, et. al. Osseointegrated implants in the treatment of partially edentulous jaws: A prospective 5-year multicenter study. Int $\mathrm{J}$ Oral Maxillofac Implants 1994;9:627-635.

5. Ruskin JD. Surgical approaches to repositioning of the inferior alveolar nerve for placement of osseointegrated implants. Atlas Oral Maxillofac Surg Clin North Am. 1994 Sep;2(2):9-20.

6. Peleg M, Mazor Z, Chaushu G, et. al. Lateralization of the inferior alveolar nerve with simultaneous implant placement: a modified technique. Int J Oral Maxillofac Implants. 2002 Jan-Feb;17(1):101-6.

7. Morrison A, Chiarot M, Kirby S. Mental nerve function after inferior alveolar nerve transposition for placement of dental implants. J Can Dent Assoc. 2002 Jan;68(1):46-50.

8. Keller EE, Eckert SE, Tolman DE. Maxillary antral and nasal one-stage inlay composite bone graft: preliminary report on 30 recipient sites. J Oral Maxillofac Surg. 1994 May;52(5):438-47; discussion 447-8.

9. Danesh-Meyer MJ. Dental Implants. Part I: Biological basis, implant types, and the peri-implant sulcus. J N Z Soc Periodontol. 1994 May;(77):15-22. Review.

10. Branemark PI, Hansson B, Adell R, et. al. Osseointegrated implants in the treatment of the edentulous jaw. Experience from a 10-year period. Scand J Plast Reconstr Surg Suppl. 1977;16:1-132. No abstract available.

11. Zablotsky $\mathrm{MH}$. A retrospective analysis of the management of ailing and failing endosseous dental implants. Implant Dent. 1998;7(3):185-91.

12. Torosian J, Rosenberg ES. The failing and failed implant: a clinical, microbiologic, and treatment review. J Esthet Dent. 1993 May-Jun;5(3):97-100. Review.

13. Koutsonikos A. Implants: success and failure--a literature review. Ann R Australas Coll Dent Surg. 1998 Oct; $14: 75-80$. Review.

14. el Askary AS, Meffert RM, Griffin T. Why do dental implants fail? Part II. Implant Dent. 1999;8(3): 265-77. Review.

15. Gouvoussis J, Sindhusake D, Yeung S. Cross-infection from periodontitis sites to failing implant sites in the same mouth. Int J Oral Maxillofac Implants. 1997 Sep-Oct;12(5):666-73.

16. Becker W, Becker BE, Newman MG, et. al. Clinical and microbiologic findings that may contribute to dental implant failure. Int J Oral Maxillofac Implants. 1990 Spring;5(1):31-8.

17. Rams TE, Link CC jr. Microbiology of failing dental implants in humans: electron microscopic observations. J Oral Implantol. 1983;11(1):93-100. No abstract available.

18. Takeshita F, Kuroki H, Yamasaki A, et. al. Histopathologic observation of seven removed endosseous dental implants. Int J Oral Maxillofac Implants. 1995 May-Jun;10(3):367-72.

19. Ibbott CG. In vivo fracture of a basket-type osseointegrating dental implant: a case report. Int $J$ Oral Maxillofac Implants. 1989 Fall;4(3):255-6.

20. Esposito M, Hirsch J, Lekholm U, et. al. Differential diagnosis and treatment strategies for biologic complications and failing oral implants: a review of the literature. Int $\mathrm{J}$ Oral Maxillofac Implants. 1999 Jul-Aug;14(4):473-90. Review.

21. Jaffin RA, Berman CL. The excessive loss of Branemark fixtures in type IV bone: a 5-year analysis. J Periodontol. 1991 Jan;62(1):2-4.

22. Fugazzotto PA, Wheeler SL, Lindsay JA. Success and failure rates of cylinder implants in type IV bone. J Periodontol. $1993 \mathrm{Nov}$;64(11):1085-7.

23. Bain CA, Moy PK. The association between the failure of dental implants and cigarette smoking. Int J Oral Maxillofac Implants. 1993;8(6):609-15. 
24. Farzad P, Andersson L, Nyberg J. Dental implant treatment in diabetic patients. Implant Dent. 2002;11(3):262-7.

25. Morris HF, Ochi S, Winkler S. Implant survival in patients with type 2 diabetes: placement to 36 months. Ann Periodontol. 2000 Dec;5(1):157-65.

26. Eriksson A, Albrektsson T, Grane B, et. al. Thermal injury to bone. A vital-microscopic description of heat effects. Int J Oral Surg. 1982 Apr;11(2):115-21.

27. Lindquist LW, Rockler B, Carlsson GE. Bone resorption around fixtures in edentulous patients treated with mandibular fixed tissue-integrated prostheses. J Prosthet Dent. 1988 Jan;59(1):59-63.

28. Ahlqvist J, Borg K, Gunne J, et. al. Osseointegrated implants in edentulous jaws: a 2-year longitudinal study. Int J Oral Maxillofac Implants. 1990 Summer;5(2):155-63.

29. Meffert RM, Langer B, Fritz ME. Dental implants: a review. J Periodontol. 1992 Nov;63(11):859-70. Review.

30. Meffert RM. Treatment of the ailing, failing implant. J Calif Dent Assoc. 1992 Jun;20(6):42-5. No abstract available.

31. Meffert RM. Maintenance and treatment of the ailing and failing implant. J Indiana Dent Assoc. 1994 Fall;73(3):22-4; quiz 25. Review.

32. Jovanovic SA. The management of peri-implant breakdown around functioning osseointegrated dental implants. J Periodontol. 1993 Nov;64(11 Suppl):1176-83. Review.

33. Rapley JW, Swan RH, Hollman WW, et. al. The surface characteristics produced by various oral hygiene instruments and materials on titanium implant abutments. Int $\mathrm{J}$ Oral Maxillofac Implants. 1990 Spring;5(1):47-52.

34. Rams TE, Link CC jr. Microbiology of failing dental implants in humans: electron microscopic observations. J Oral Implantol. 1983;11(1):93-100. No abstract available.

35. Lindhe J, Berglundh T, Ericsson L, et. al. Experimental breakdown of peri-implant and periodontal tissues. A study in the beagle dog. Clin Oral Implants Res. 1992 Mar;3(1):9-16.

36. Mombelli A. Etiology, diagnosis, and treatment considerations in peri-implantitis. Curr Opin Periodontol. 1997;4:127-36. Review.

37. Mombelli A, Lang NP. Antimicrobial treatment of peri-implant infections. Clin Oral Implants Res. 1992 Dec;3(4):162-8.

38. Quirynen M, Naert I, van Steenberghe D. Fixture design and overload influence marginal bone loss and fixture success in the Branemark system. Clin Oral Implants Res. 1992 Sep;3(3):104-11.

39. Rangert B, Jemt T, Jorneus L. Forces and moments on Branemark implants. Int J Oral Maxillofac Implants. 1989 Fall;4(3):241-7.

40. Matarasso S, Quaremba G, Coraggio F, et. al. Maintenance of implants: an in vitro study of titanium implant surface modifications subsequent to the application of different prophylaxis procedures. Clin Oral Implants Res. 1996 Mar;7(1):64-72.

41. McCollum J, O'Neal RB, Brennan WA, et. al. The effect of titanium implant abutment surface irregularities on plaque accumulation in vivo. J Periodontol. 1992 Oct;63(10):802-5..

42. Glossary of Periodontal Terms. American Academy of Periodontology. 3rd edition 1992.

43. Jovanovic SA, Kenney EB, Carranza FA, et. al. The regenerative potential of plaque-induced periimplant bone defects treated by a submerged membrane technique: an experimental study. Int $J$ Oral Maxillofac Implants. 1993;8(1):13-8.

44. Wittrig EE, Zablostsky MH, Layman DL, et. al. Fibroblastic growth and attachment on hydroxyapatite-coated titanium surfaces following the use of various detoxification modalities. Part I: Noncontaminated hydroxyapatite. Implant Dent. 1992 Fall;1(3):189-94.

45. Zablotsky MH, Wittrig EE, Diedrich DL, et. al. Fibroblastic growth and attachment on hydroxyapatitecoated titanium surfaces following the use of various detoxification modalities. Part II: Contaminated hydroxyapatite. Implant Dent. 1992 Fall;1(3):195-202.

46. Velasquez-Plata D, Scheyer ET, Mellonig JT. Clinical comparison of an enamel matrix derivative used alone or in combination with a bovine-derived xenograft for the treatment of periodontal osseous defects in humans. J Periodontol. 2002 Apr;73(4):433-40.

47. Wenz B, Oesch B, Horst M. Analysis of the risk of transmitting bovine spongiform encephalopathy through bone grafts derived from bovine bone. Biomaterials. 2001 Jun;22(12):1599-606. 
48. Moskow BS, Karsh F, Stein SD. Histological assessment of autogenous bone graft. A case report and critical evaluation. J Periodontol. 1979 Jun;50(6):291-300.

49. Mellonig JT, Bowers GM, Cotton WR. Comparison of bone graft materials. Part II. New bone formation with autografts and allografts: a histological evaluation. J Periodontol. 1981 Jun;52(6):297-302.

50. Drury GI, Yukna RA. Histologic evaluation of combining tetracycline and allogeneic freeze-dried bone on bone regeneration in experimental defects in baboons. J Periodontol. $1991 \mathrm{Nov} ; 62(11): 652-8$.

51. Urist MR. Bone: formation by autoinduction. Science. 1965 Nov 12;150(698):893-9. No abstract available.

52. Reddi $A H$, Huggins $C$. Biochemical sequences in the transformation of normal fibroblasts in adolescent rats. Proc Natl Acad Sci U S A. 1972 Jun;69(6):1601-5. No abstract available.

53. Shigeyama Y, D'Errico JA, Sonte R, et. al. Commercially-prepared allograft material has biological activity in vitro. J Periodontol. 1995 Jun;66(6):478-87.

54. Lozada JL, James RA, Boskovic M, et. al. Surgical repair of peri-implant defects. J Oral Implantol. 1990;16(1):42-6. No abstract available.

55. Boyne PJ, Shabahang S. An evaluation of bone induction delivery materials in conjunction with rootform implant placement. Int J Periodontics Restorative Dent. 2001 Aug;21(4):333-43.

56. Lozada JL, James RA, Boskovic M, et. al. Surgical repair of peri-implant defects. J Oral Implantol. 1990;16(1):42-6. No abstract available.

57. Passi P, Girardello G, Piattelli $A$, , et. al. Synthetic bone grafts in peri-implant bone dehiscences: histological results in humans. Gen Dent. 1999 May-Jun;47(3):290-5.

58. Bauman GR, Mills M, Rapley JW, et. al. Clinical parameters of evaluation during implant maintenance. Int J Oral Maxillofac Implants. 1992 Summer;7(2):220-7. Review.

\section{About the Authors}

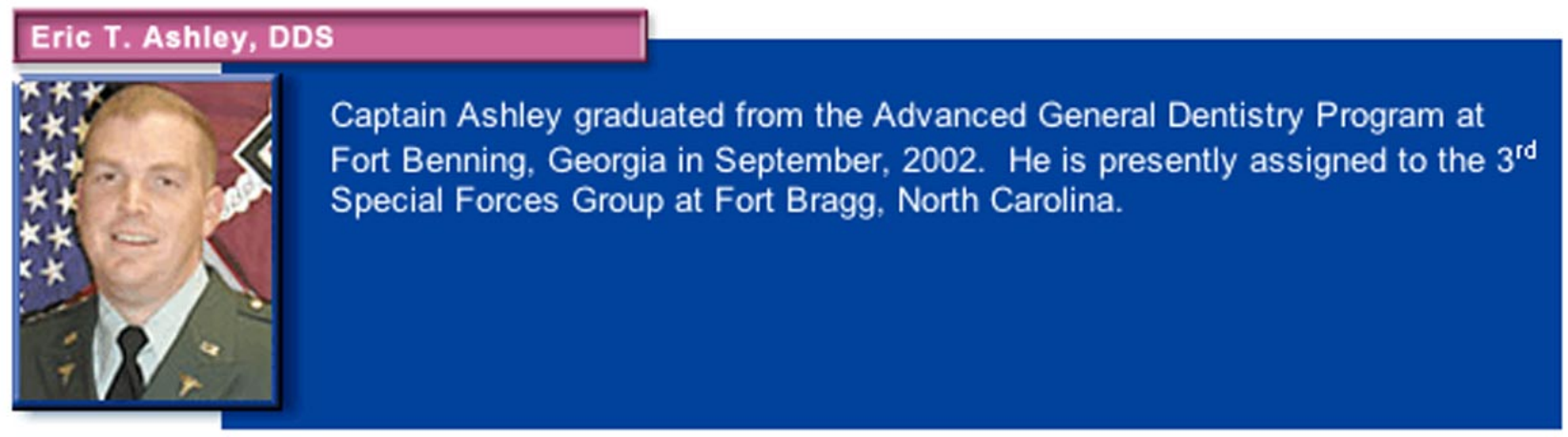

\section{Lemuel L. Covington, DMD}

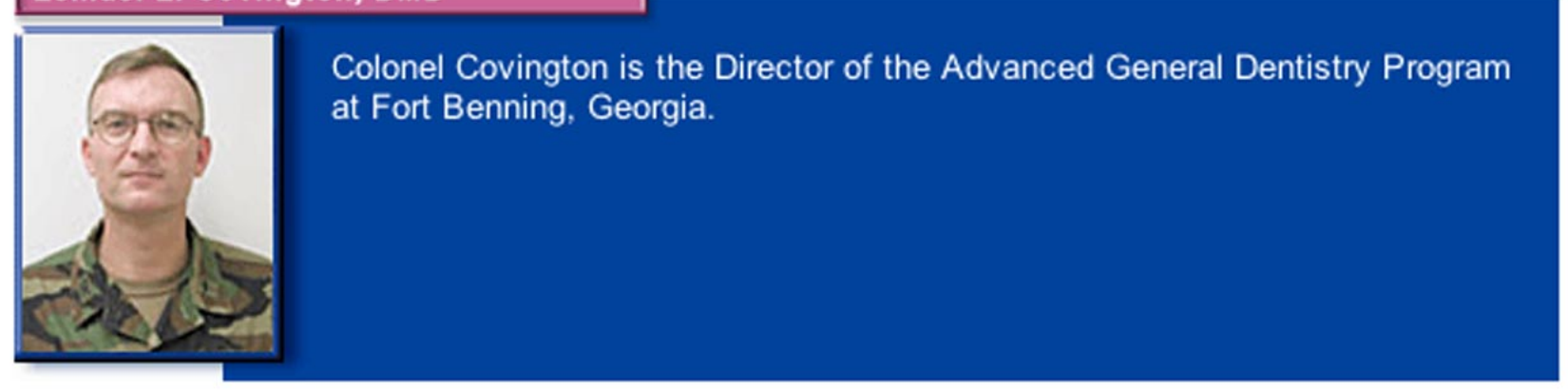




\section{Barry G. Bishop, DDS}

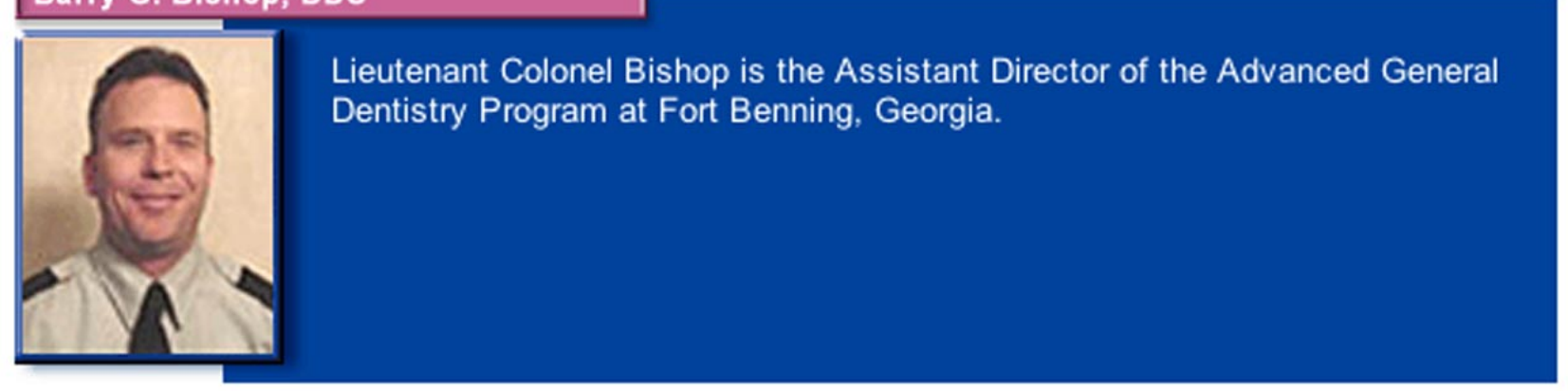

\section{Lawrence G. Breault, DMD, MS}

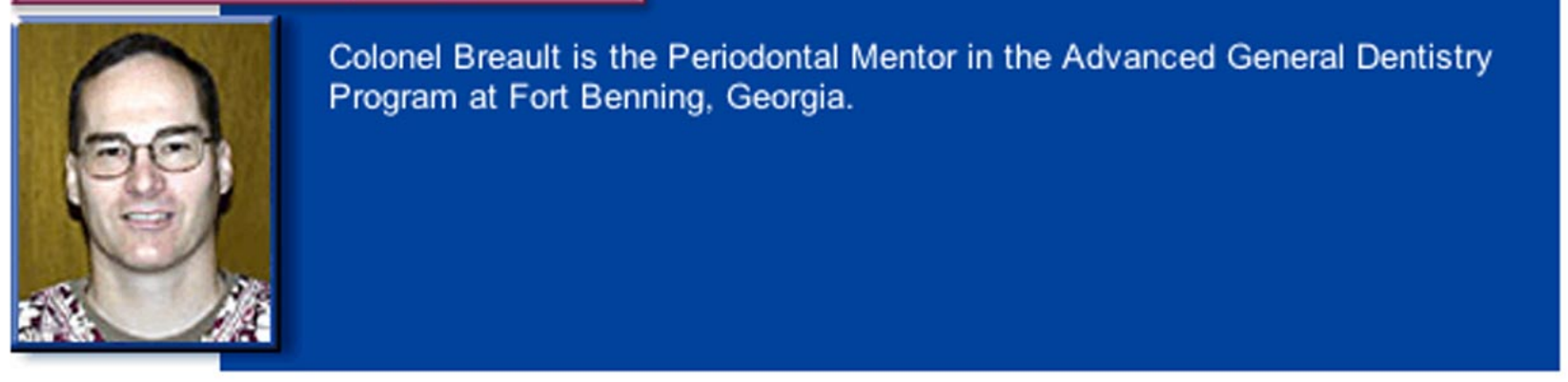

"The authors thank the following individuals for their photo contributions: Dr. Edward B. Fowler, Puyallup, WA, Dr. Bruce A. Boretsky, Columbus, GA and Dr. Thomas Anderson of the Canadian Forces Dental Services." 